\title{
Resenha
}

\section{A internacionalização das políticas educacionais e seus principais atores}

\author{
Mari Valicheski Ferrari \\ Instituto Federal de Brasília
}

AKKARI, Abdeljalil. Internacionalização das políticas educacionais: transformações e desafios. Petrópolis: Vozes, 2011.

Podemos começar nos questionando o que é a internacionalização das políticas educacionais. 0 que os organismos de cooperação bilateral e multilateral têm a ver com a redução dos gastos no ensino público e o aumento da pressão sobre os professores? Ou ainda, qual é o impacto da globalização no contexto educacional? Estas e outras questões são pontualmente discutidas na obra de Abdeljalil Akkari que trata das transformações e desafios na internacionalização das políticas educacionais.

Primeiramente o autor esclarece que uma política educacional visa adequar os serviços prestados pelos sistemas educacionais às necessidades sociais de educação. É um conjunto de decisões que visam atender às expectativas da sociedade em relação à educação.

As mudanças relativas às políticas educacionais nos últimos anos estão intimamente relacionadas à forma comercial como a educação vem sendo tratada, e a influência de organismos internacionais tais como o Banco Mundial e o Fundo Monetário Internacional.

Nesta obra são pontuados aspectos positivos da globalização, tais como: 0 apoio mútuo, a comunicação e a cooperação entre países e regiões; e acentuados aspectos negativos, especialmente quanto ao aumento da desigualdade e quanto à promoção de culturas e valores de países desenvolvidos. As implicações da globalização na educação são muito mais profundas e contundentes, pois "ela está no centro das tensões entre o local e o global” (Akkari, 2011, p. 23). A globalização tem incentivado a formação de indivíduos com as competências transversais, voltadas à mobilidade.

Organizações internacionais que por muitas décadas contribuíram para a formulação de políticas educacionais como Unesco e Unicef, criadas após a Segunda Guerra Mundial, sofreram um enfraquecimento. A Unesco, especialmente, perdeu 
força com a saída de seus maiores financiadores, os Estados Unidos e o Reino Unido, em 1980. Passaram a atuar fortemente na esfera educacional o Banco Mundial e o Fundo Monetário Internacional (FMI).

O Banco Mundial, com o propósito claro de inserir indivíduos na economia, tem como algumas de suas prioridades: dedicar metade dos gastos com educação básica, incentivar a participação do setor privado, especialmente no ensino médio e superior - como forma de redução da participação do Estado - e descentralizar a gestão da educação, priorizando assim a mobilidade e a reforma dos currículos.

Apesar das contradições externas, os atores envolvidos nas estratégias globais de cooperação, especialmente os líderes locais, começam a se conscientizar quanto à forma assimétrica e, algumas vezes, neocolonial, das relações de cooperação para o desenvolvimento internacional.

Nos países desenvolvidos, os organismos de maior influência são a Organização para Cooperação e Desenvolvimento Econômico (OCDE) e a Organização Mundial do Comércio (OMC). A OCDE estabeleceu um regime internacional comparativo, que vem influenciando as políticas educacionais de diversos países. 0 Programa Internacional de Avaliação de Alunos lem inglês, Programme for International Student Assessment - PISAl é um exemplo deste regime. Estudos como este visam à competitividade econômica internacional, estabelecendo uma nova relação de concorrência e inserindo no contexto educacional grandes corporações, o que, para a OCDE, é uma importante opção política.

A ampliação dos mercados e as novas relações existentes trouxeram uma tendência à descentralização. Descentralizar envolve a transferência de poder e autoridade para outro nível, diferente ou inferior. Mas em relação à educação, a descentralização é positiva? Ela traz benefícios? A gestão descentralizada é mais eficaz? A pesquisa apresentada no livro demonstra que o desempenho dos alunos é melhor em países que possuem um sistema centralizado. Entretanto, o autor deixa claro que essas questões ainda precisam ser mais exploradas.

É apresentada uma discussão bastante interessante sobre descentralização com autores como McGinn e Welsh (1999), Bouvier (2007), Lauglo (1995), Lagier e Diarra (2006), Vinokur (2003), destacando-se que nenhum sistema educacional é completamente centralizado ou completamente descentralizado.

0 entusiasmo pela descentralização tem como principais fatores a obrigação de prestar contas (accountability) e o desenvolvimento de políticas neoliberais, tais como: ampliação das forças de mercado, enfraquecimento do Estado-nação, direito de os trabalhadores se tornarem responsáveis por suas decisões e aplicação dos sistemas dominantes dos países desenvolvidos.

A partir da década de 1990, a educação passou a atrair investidores, tornando-se uma estratégia de diversificação em tempos de crise econômica. As privatizações, 
fortemente influenciadas pelos governos de R. Reagan e M. Thatcher, e por pensadores como o economista, prêmio Nobel, Milton Friedman (1912-2006), mudaram a visão de escolarização, passando a prevalecer o julgamento pelo desempenho, tanto para alunos, quanto para professores.

As fronteiras entre ensino público e privado têm se tornando indefinidas. 0 setor privado tem penetrado no sistema educacional de diversas formas, muitas vezes camuflado nas privatizações, ou então como subvenções, como no caso dos vouchers educacionais. No Brasil temos o exemplo do grupo Positivo e das várias escolas de idiomas, grupos de franquias com modelos e padrões espalhados pelo mundo e que se utilizam de técnicas dissimuladas de seleção dos melhores.

Mas quem se beneficia com a indefinição dos limites entre as redes de ensino pública e privada? Analisando-se a evolução das matrículas no ensino fundamental na tabela apresentada no livro, nota-se uma diminuição do número de matrículas na rede pública. As elites priorizam a educação básica, que possui menor investimento governamental, na rede privada e usufruem da educação pública no nível superior, que tem maior investimento governamental, ou seja, o poder público gasta mais com os grupos favorecidos do que com as classes desfavorecidas.

Exemplos que confirmam esta tendência são o Enem e o ProUni. As escolas particulares oferecem ensino voltado a obter a melhor nota no Enem. Das escolas com melhor classificação no Enem, apenas $8 \%$ são públicas. Estes e outros dados relativos à distribuição das universidades no país, ao financiamento público no setor privado, às parcerias público-privadas e ao fornecimento de material pedagógico formatado para o ensino público pelo setor privado, demonstram que a indefinição dos limites entre educação pública e privada constitui-se como o principal instrumento de manutenção das desigualdades sociais.

A globalização, as descentralizações, as privatizações e a accountability têm definido padrões educacionais que se refletem em políticas educacionais cada vez mais voltadas a medir o desempenho dos alunos. No Brasil isso pode ser visto em exames como Enem, Saeb e Prova Brasil. Os projetos financiados pelo Banco Mundial em vários estados brasileiros têm como premissas qualidade, descentralização e responsabilização.

Essa corrente mundial refletida na política educacional do país tem impacto também sobre a formação dos professores. Percebe-se, na realidade, uma desprofissionalização. A tentativa de universitarização da formação docente tem enfrentado dificuldades. A flexibilização nos contratos de trabalho dos professores e a introdução de outros tipos de trabalhadores, tais como consultores e trabalhadores por projeto, têm demonstrado a transferência de valores profissionais para valores puramente mercadológicos.

0 objetivo deste texto foi mostrar um pouco do que Abdeljalil Akkari trata em 
sua obra, não a ponto de extinguir a curiosidade dos leitores, mas de instigar ainda mais os que buscam perceber e conhecer a rede de inter-relações, nem sempre visível, entre os principais atores das políticas educacionais.

Aobraéindicada para todosaquelesque têm interesse sobreainternacionalização das políticas educacionais. 0 tema é atual e instigante, especialmente aos que estão iniciando os estudos nessa área, estudantes da graduação e pós-graduação. A obra traz o arcabouço teórico que ampliará a visão acerca do assunto, bem como questões para discussão ao final de cada capítulo, que ampliam os debates e incentivam ainda mais as pesquisas.

Recebido em outubro de 2013

Aprovado em dezembro de 2013

Mari Valicheski Ferrari é mestranda em Educação do Programa de Pós-Graduação em Educação da Universidade Católica de Brasília e docente de Administração do Instituto Federal de Brasília (IFB). E-mail: mari.valicheskidgmail.com 